\title{
Diarrhea Among International Travelers in Bali- Indonesia: Clinical and Microbiological Finding
}

\author{
Sri Masyeni ${ }^{1 *}$, Hegard Sukmawati ${ }^{1}$, Lila Paramasatiari ${ }^{1}$, Sri Agung Aryastuti ${ }^{1}$, Ketut Agus Somia $^{2}$, Gede \\ Kambayana ${ }^{2}$, Nyoman Astika², Renny Duarsa ${ }^{3}$, Tuti Parwati Merati²
}

${ }^{1}$ Departement of Internal Medicine, Faculty of Medicine and Health Science, Warmadewa University, Bali, Indonesia

${ }^{2}$ Faculty of Medicine, Udayana University, Bali, Indonesia

${ }^{3}$ Kasih Ibu Hospital Denpasar, Bali, Indonesia

Corresponding Author: Sri Masyeni, MD, Departement of Internal Medicine, Faculty of Medicine and Health Science, Warmadewa University, Jln Terompong 24, Denpasar, Bali, Indonesia. Tel: +628113960099, Email: sri.masyeni@

warmadewa.ac.id

Received June 22, 2017; Accepted August 3, 2017; Online Published August 23, 2017

\begin{abstract}
Introduction: Diarrhea is a common illness among travelers to developing countries. Located in a tropical region, Bali has a potentially high prevalence of travelers diarrhea. This hospital-based cross-sectional study was carried out to assess the clinical and microbiological profiles of diarrhea among travelers admitted to Kasih Ibu hospital, Denpasar-Bali.

Methods: This study enrolled a total of 71 patients at Kasih Ibu hospital between April 2015 and August 2016. All patients completed an epidemiologic questionnaire; their clinical histories were taken, and physical examinations were performed. Stool samples were collected for bacterial and parasitologic studies and susceptibility testing.

Results: Most patients were female $(70.4 \%)$, and the nationality of most patients was Dutch $(15.5 \%)$. Secretory diarrhea was the most frequently found diarrheal type $(88.7 \%)$, with only $5.6 \%$ of cases having severe dehydration which developed into acute kidney injury. A high percentage of Entamoeba spp. was also seen in this study (54.9\%). Of the 37 stool samples available for microbiological testing, $62.2 \%$ showed growth; Escherichia coli was the most commonly isolated bacteria (54.1\%). Patients not infected by Entamoeba spp. were found more likely to experience nausea and vomiting $(P<0.005)$.

Conclusion: Secretory diarrhea was the most prevalent type of diarrhea among travelers admitted to Kasih Ibu hospital, Bali. The most frequently found pathogens were Entamoeba spp. and E. coli. Although most patients had only mild dehydration as a complication, acute kidney injury did occur in some cases.

Keywords: Diarrhea, Entamoeba, Escherichia coli
\end{abstract}

Citation: Masyeni S, Sukmawati H, Paramasatiari L, et al. Diarrhea among international travelers in Bali-Indonesia: clinical and microbiological finding. Int J Travel Med Glob Health. 2017;5(3):84-88. doi:10.15171/ijtmgh.2017.18.

\section{Introduction}

Diarrhea remains the most common illness affecting travelers. ${ }^{1,2}$ During their stay abroad, at least one episode of diarrhea occurs in $20 \%-50 \%$ of travelers. ${ }^{3}$ It is estimated that about 15-20 million travelers experience traveler's diarrhea annually. ${ }^{4}$ Risk factors of diarrhea for travelers are varied according to the selected destination, age, behavior, genetic susceptibility, and nationality of the travelers. ${ }^{4,5}$ The incidence rate of traveler's diarrhea can range from $5 \%$ to $50 \%$ depending on the destination. Travelers originating from developing countries have a relatively low incidence rate of traveler's diarrhea, while travelers from developed countries tend to experience higher incidence rates. The most common bacteria causing these diarrhea cases are Escherichia coli, Shigella, Campylobacter, Salmonella, Aeromonas, Plesiomonas, and non-cholera vibrios. ${ }^{6,7}$ Traveler's diarrhea significantly impacts patients not only during the course of their travel, but also following their journey home. These cases may develop into persistent diarrhea with the risk of developing into irritable bowel syndrome. ${ }^{8,9}$ Bali has a fastgrowing tourism industry and has been named one of the busiest travel destinations in Southeast Asia, with around 6.7 million international visits annually. ${ }^{10}$ Located in a tropical region, Bali may unsurprisingly have a high prevalence of diarrhea among travelers. Currently, there are no published studies that have focused on the profile of diarrhea among travelers in Indonesia. This study aimed to assess the clinical characteristics and etiologies of diarrhea among travelers

Copyright $\odot 2017$ The Author(s). This is an open-access article distributed under the terms of the Creative Commons Attribution License (http:// creativecommons.org/licenses/by/4.0), which permits unrestricted use, distribution, and reproduction in any medium, provided the original work is properly cited. 
admitted to Kasih Ibu hospital, Bali. The results of this study will hopefully contribute to a better understanding of the characteristics of diarrhea affecting travelers visiting Bali and serve as a basis for recommendations of future study on reducing the effects of travelers diarrhea.

\section{Methods}

Study Population/Recruitment

This study was a single site, prospective cross-sectional, hospital-based study conducted at Kasih Ibu hospital in Bali, Indonesia, which is the hospital referred to international travelers to Bali. The patients recruited were adult international travelers who suffered diarrhea during their stay in Bali. Consecutive-sampling was conducted from April 2015 to August 2016. The inclusion criteria were adult travelers (age $\geq 18$ years), admission to Kasih Ibu hospital for diarrhea (frequency $\geq 3$ times a day), and agreement to participate in the study by signing a written informed consent form. Exclusion criteria were incomplete data, insufficient stool samples, and food intolerance diarrhea. A total of 71 international travelers who met the inclusion criteria were included in this study. The patients were required to fill out a standardized epidemiological questionnaire; they were also interviewed about clinical symptoms and asked to provide stool samples.

\section{Definitions}

Diarrhea is defined as the passage of three or more watery stools or any number of unformed or loose stools within a 24hour period, with or without one of the following symptoms: nausea, vomiting, abdominal pain or cramps, fever. Diarrhea is classified as chronic when its duration is more than 2 weeks. Cases not fulfilling these criteria were defined as acute diarrhea. Secretory diarrhea was defined as feces with large amount of water, whereas inflammatory diarrhea was defined as loose stool with the presentation of mucus and/or blood in the stool. The dehydration grading was classified as mild, moderate, or severe according to Duggan et $\mathrm{al}^{11}{ }^{11}$ and the World Health Organization. ${ }^{12}$ Hyponatremia was indicated by a sodium level less than $135 \mathrm{mEq} / \mathrm{L}$, while hypokalemia was indicated by a potassium level less than $3.5 \mathrm{mEq} / \mathrm{L}$. Bacterial diarrhea in travelers was diagnosed based on the detection of leukocytosis in the stool sample ( $>5$ leukocyte/high-power field) or enteric pathogen in the stool sample accompanied by fever (temperature $\geq 37.5^{\circ} \mathrm{C}$ )..$^{13}$ The classification of Entamoebic diarrhea in travelers was based on the detection of the cyst or vegetative form of Entamoeba spp.

\section{Data Collection}

Data extracted from the questionnaire included demographic information (name, age, gender, nationality), type of restaurant, and type of food consumed in the previous 2 days. Interviews were also conducted to retrieve information on type and frequency of diarrhea and concomitant symptoms. Physical examinations were performed to assess the severity of diarrhea by evaluating blood pressure, pulse rate, presentation of sunken eyes, skin turgor, vox cholerica, facies cholerica, clammy limbs, and urine production in the previous 6 hours. Blood was drawn to test for cell blood count, blood urea nitrogen, creatinine, transaminases, blood glucose, and electrolyte levels. Fresh stool samples were collected on admission in 2 different containers for stool tests and stool cultures.

Microbiological and Parasite Identification

Microbiological and parasite identification tests were conducted at the Clinical Microbiology Laboratory of Kasih Ibu hospital and Quantum Laboratory. Stool samples were stored at $4^{\circ} \mathrm{C}$ in Cary-Blair transport medium for bacteria culture examination. Each specimen was inoculated in MacConkey agar selective media and Xylose Lysine Deoxycholate agar media, and then incubated at $37^{\circ} \mathrm{C}$ for 24-48 hours. API test was used to confirm the presence of Escherichia coli/Enterobacter. Antimicrobial resistance tests used the disc diffusion Kirby-Bauer method. The antimicroba used were ampicillin, sulfamethoxazole-trimethoprim, chloramphenicol, tetracycline, cephalothin, ceftriaxone, colistin, kanamycin, neomycin, erythromycin, nalidixic acid, norfloxacin and ciprofloxacin.

\section{Statistical Analysis}

The propotional data was described according to their characteristics and the categorical variables were analyzed using a chi-square test. A $P$ value of less than 0.05 was considered statistically significant.

\section{Results}

\section{Patient Characteristics}

A total of 71 foreign patients were enrolled in this study. Of the 71 patients, $50(70.4 \%)$ were female and $21(29.6 \%)$ were male (Table 1 ). Patients were predominantly $(73.2 \%)$ young adults ranging in age from 18 to 44 years, with the median age being 27 years. The most common nationalities were Dutch (15.5\%), Russian (12.7\%) and Australian (8.5\%) (Figure 1).

\section{Clinical Features}

Patients in this study experienced an average duration of diarrhea of 3 days. The median frequency of diarrhea was 7 times (within the range of 2-30 times). The type of diarrheal mechanism was mostly secretory (88.7\%); only $11.3 \%$ of the

Table 1. Demographic Profile of Travelers With Diarrhea at Kasih Ibu Hospital

\begin{tabular}{ll}
\hline Parameters & Total $(\mathbf{n}=\mathbf{7 1})$ \\
\hline Sex & \\
Male & $21(29.6)$ \\
Female & $50(70.4)$ \\
Age & \\
$\leq 17$ (Adolescent) & $6(8.5)$ \\
18-44 (Young adulthood) & $52(73.2)$ \\
45-64 (Late adulthood) & $8(11.3)$ \\
$\geq 65$ (Elderly) & $5(7.0)$ \\
\hline
\end{tabular}




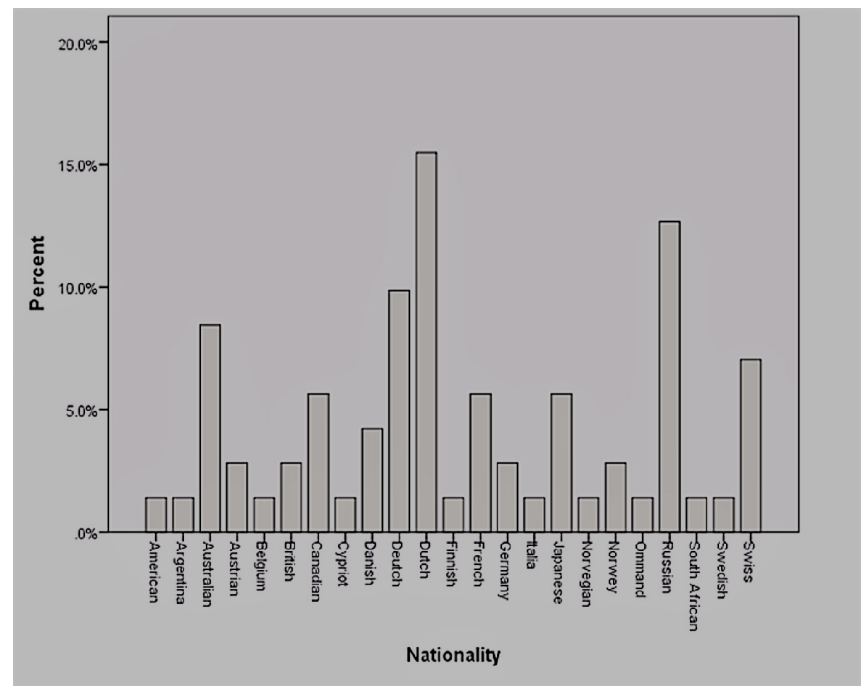

Figure 1. Nationality.

cases were inflammatory. Patients experienced various enteric symptoms, the most frequent ones being abdominal cramps (74.6\%), nausea (70.4\%), and vomiting (50.7\%); only 8 patients had blood in their stools. Of the 71 travelers with diarrhea, 40 patients (56.3\%) experienced mild dehydration, 27 (38.0\%) had moderate dehydration, and severe dehydration occurred in 4 patients (5.6\%). The 4 patients with severe dehydration developed acute kidney injury. Other complications noted were hyponatremia (40.8\%) and hypokalemia (25.4\%) (Table 2).

The distribution of body temperature was skewed to the right with $40.8 \%$ of patients having lower than normal $\left(36^{\circ} \mathrm{C}\right)$ body temperature. Patients' blood pressure rates and blood test results for hemoglobin, platelets, white blood cells, and hematocrit were normal on average. As shown in Table 3, only 37 samples were available for pathogen identification; $37.8 \%$ of the samples showed no growth. E. coli was the most commonly isolated enteropathogen in the samples (54.1\%).

As an additional analysis, the clinical characteristics of patients with and without Entamoeba spp. in their stools were compared. As summarized in Table 2, 39 fecal samples (54.9\%) contained Entamoeba spp. Based on chi-square and Fisher exact test results, it was determined that there were statistically significant differences in the proportion of nausea and vomiting symptoms between patients having Entamoebic spp. and those having no Entamoebic spp $(P<0.05)$.

\section{Discussion}

This is the first report of travelers diarrhea from a tourism destination in Indonesia. This study presents a number of important findings. First, the most predominant age range of cases in this study was young adulthood. This may be attributable to the fact that people in this age range are usually the most adventurous travelers. They may feel more challenged to try local foods and beverages during their stay abroad, thus increasing their risk of contracting gastrointestinal infection. This result is in agreement with those of Ahn et al, ${ }^{14}$ and Gascón, ${ }^{15}$ who concluded that the age range with the highest prevalence of diarrhea amongst travelers is 20-39 years old, and children and young adults experience more diarrheal episodes than any other age groups. Second, the social economic status of a person is a factor in one's risk of catching this disease. Moreover, being the most adventurous, younger tourists are commonly less well-off economically compared with older tourists; thus, the likelihood they will contract

Table 2. Clinical Comparison of Patients With Stools Containing Entamoeba spp. and Patients With Non-Entamoeba spp.

\begin{tabular}{|c|c|c|c|}
\hline Parameters & $\begin{array}{c}\text { Entamoeba spp } \\
(\mathrm{n}=39)\end{array}$ & $\begin{array}{c}\text { Non-Entamoeba } \\
(\mathrm{n}=32)\end{array}$ & $P$ Value \\
\hline \multicolumn{4}{|l|}{ Symptoms, No. (\%) } \\
\hline Cramps & $30(76.9)$ & $23(71.9)$ & 0.627 \\
\hline Nausea & $22(56.4)$ & $28(87.5)$ & $0.005^{\mathrm{ab}}$ \\
\hline Vomiting & $13(33.3)$ & $23(71.9)$ & $0.001^{\mathrm{b}}$ \\
\hline Fever & $16(41)$ & $11(34.4)$ & 0.78 \\
\hline Blood in stool & $7(17.9)$ & $1(3.1)$ & $0.065^{\mathrm{a}}$ \\
\hline Mucus in stool & $7(17.9)$ & $1(3.1)$ & $0.065^{\mathrm{a}}$ \\
\hline \multicolumn{4}{|l|}{ Diarrhea profile, No.(\%) } \\
\hline Secretory & $32(82.1)$ & $31(96.9)$ & $0.065^{\mathrm{a}}$ \\
\hline Inflammatory & $7(17.9)$ & $1(3.1)$ & $0.065^{\mathrm{a}}$ \\
\hline \multicolumn{4}{|l|}{ Dehydration, No.(\%) } \\
\hline Mild & $21(53.8)$ & $19(59.4)$ & \\
\hline Moderate & $15(38.5)$ & $12(37.5)$ & 0.806 \\
\hline Severe & $3(7.7)$ & $1(3.1)$ & $0.614^{\mathrm{a}}$ \\
\hline Hypokalemia, No.(\%) & $9(23.1)$ & $9(28.1)$ & 0.627 \\
\hline Hyponatremia, No.(\%) & $12(30.8)$ & $17(53.1)$ & 0.057 \\
\hline
\end{tabular}

a Fisher exact test.

${ }^{\text {b }}$ Statistically significant.

Mild is the reference for dehydration variable. 
Table 3. Identified Microorganisms

\begin{tabular}{lcc}
\hline Microorganism Identification Test & No. & \% \\
\hline Bacteria & 37 & \\
Escherichia coli & 20 & 54.1 \\
No Growth & 14 & 37.8 \\
Enterobacter & 1 & 2.7 \\
Klebsiella pneumonia & 1 & 2.7 \\
Shigella spp. & 1 & 2.7 \\
Parasites & 71 & \\
Entamoeba spp. & 39 & 54.9 \\
Non-Entamoeba spp. & 32 & 45.1 \\
\hline
\end{tabular}

diarrhea is further increased. Third, the results revealed that the most common nationality to contract diarrhea was Dutch, followed by Russian. Dutch and Russian travelers are possibly more susceptible to diarrhea because of their less frequent visits to developing countries. However, the third nationality with the highest number of patients was Australians. Being one of Indonesia's closest neighbors, Australia naturally sends large numbers of tourists to Indonesia every year. The high proportion of Australians visiting Bali contributes to an equally higher propensity of Australian patients to outnumber patients from other countries.

More than $95 \%$ of cases in this study were acute diarrhea. It is suspected that the fast onset of diarrhea was caused by enterotoxigenic E. coli (ETEC) and possibly enteroaggregative E. coli (EAEC). Both E. coli strains are known to have fast onset ranging from 8-48 hours. Other studies ${ }^{2,16,17}$ have stated that the major causes of diarrhea in travelers are ETEC, Shigella, and Campylobacter. Only a small portion of cases are caused by intestinal parasites such as the Entamoeba species, Giardia species, and Cryptosporidium parvum species. ${ }^{18}$ Another case report published by $\mathrm{Yu}$ and Sohn ${ }^{19}$ provided evidence that Cyclospora is a culprit for traveler's diarrhea among tourists visiting Indonesia. To confirm this, microbiological tests were conducted on the stools in this study; E. coli was found to be the most isolated bacteria. The reason behind this might also be related to the high endemicity of this pathogen in developing countries. There were 37 stool samples available for the microbiological test, of which $37.8 \%$ showed no growth. Virus might also be incriminated for the diarrhea cases. However, further research is needed to confirm this suspicion as virological testing was not conducted in this study.

The most common type of diarrhea seen was secretory, the mechanism of which is usually exhibited by ETEC. The diarrhea caused by this pathogen is watery and noninflammatory. Non-inflammatory diarrhea could also be caused by the osmotic mechanism carried by the rotavirus. ${ }^{20}$ This high case rate of non-inflammatory diarrhea is coherent with the microbiological findings of the current study.

The patients in this study mostly experienced cramps, nausea, and vomiting, which normally happen in patients with acute non-inflammatory diarrhea. These clinical symptoms are the manifestations of small intestine disturbance caused by high volume watery stool and dehydration. There were significant differences between electrolyte imbalance caused by hiponatremia and hipokalemia, which may be related to dehydration.

Patients with Entamoeba spp. present in their stools were less likely to experience nausea and vomiting during their diarrheal episodes, and their diarrheal profile was mostly secretory. Classically, the manifestation of diarrhea related to Entamoeba hystolytica is dysentric or bloody diarrhea due to the invasion of this pathogen into the intestinal mucosal. Further investigation is required to assess whether there was any association between immunity in the travelers (nonimmune) and the different clinical symptoms (secretory manifestation) found in this study. Differences in results obtained in this study compared with previously published data may be due to the possibility that other pathogens besides Entamoeba spp were involved in the infection. The great amount of parasites Entamoeba spp. in stool samples of the present study differs from the results obtained by Murphy and Pandey, ${ }^{21}$ who reported Campylobacter, ETEC, Shigella, and Cyclospora as the most commonly found pathogens incriminated for causing diarrhea in travelers in Nepal, while the parasite Giardia was a less common cause. Meanwhile, the findings of the current study match those of Peltola and Gorbach $^{22}$ and Taylor et $\mathrm{al}^{23}$ in which protozoans (Giardia and Entamoeba spp.) were the most common pathogen found to cause traveler's diarrhea. ${ }^{18}$ In fact, no data as of yet published in scientific journals has shown local cases of infection caused by Entamoeba spp. In the current study, 17 of 37 samples showed multiple pathogens present in the stool (data not shown). However, further analysis and a more robust study with a larger data set are required to confirm this.

\section{Conclusion}

The most common diarrhea cases among international travelers in Bali was secretory diarrhea without severe complication. E. coli was the main microorganism found in the patients' stool samples. However, Entamoeba spp., which is usually the main culprit for inflammatory diarrhea, was also found among samples with secretory diarrhea.

\section{Study Limitations}

This study has some limitations. First, clinical scoring was used to define the levels of dehydration. This type of scoring may give some error related to clinical judging (more subjective) than of using other more objective tools in defining dehydration. Second, the authors could not unreservedly differentiate between the species of Entamoeba spp. as the cause of diarrhea in travelers using only the microscopic test; this test is too sensitive and dependant on the skills of the laboratorist. More sophisticated tools are needed to differentiate between the species of this amoeba. Reverse line blot hybridization assay or polymerase chain reaction may be a better option for future research to confirm the species of the Entamoeba spp. as responsible for diarrhea in travelers. Detection of virus as the cause of diarrhea in travelers may also be needed in future research. 


\section{Authors' Contributions}

SM conceived and designed the study, collected the data, completed the analyses, and co-authored the manuscript. HS conducted the statistical analyses. LP performed the background literature review for the manuscript. SAA performed the background literature review and co-authored the manuscript. KAS, GK, NA, RD, and TPM provided intellectual support and critically edited the work. All authors reviewed and approved the final version of the manuscript.

\section{Conflict of Interest Disclosures}

The authors declare that they have no conflicts of interest.

\section{Ethical Approval}

This study was conducted with approval from the Medical Research Ethics Committee of the Faculty of Medicine, Udayana University (document number 1510/UN.14.2/ Litbang/2015). All study patients were enrolled after having provided written informed consent.

\section{Funding/Support}

This Research Project was fully sponsored by research grant from Faculty of Medicine and Health Science of Warmadewa University.

\section{Acknowledgments}

The authors thank the patients who agreed to participate in this study. Particular thanks go to the doctors, nurses, and the laboratorist in Kasih Ibu Hospital Denpasar and Quantum Laboratory, Denpasar, Bali for their great support and participation in the study. Further thanks goes to Dr. Putu Sutisna, DTM, SpPAr(K) for a critical review of the article's manuscript.

\section{References}

1. Fox TG, Manaloor JJ, Christenson JC. Travel-related infections in children. Pediatr Clin North Am. 2013;60(2):507-527. doi:10.1016/j.pcl.2012.12.004.

2. Steffen R, Hill DR, DuPont HL. Traveler's diarrhea: a clinical review. JAMA. 2015;313(1):71-80. doi:10.1001/jama.2014.17006.

3. Casburn-Jones AC, Farthing MJ. Traveler's diarrhea. J Gastroenterol Hepatol. 2004;19(6):610-8. doi:10.1111/j.14401746.2003.03287.x.

4. Steffen R. Epidemiology of traveler's diarrhea. Clin Infect Dis. 2005;41 Suppl 8:S536-S540. doi:10.1086/432948.

5. Yates J. Traveler's diarrhea. Am Fam Physician. 2005;71(11):20952100.

6. de la Cabada Bauche J, DuPont HL. New developments in traveler's diarrhea. Gastroenterol Hepatol. 2011;7(2):88-95.

7. Kollaritsch H, Paulke-Korinek M, Wiedermann U. Traveler's diarrhea. Infect Dis Clin North Am. 2012;26(3):691-706. doi:10.1016/j.idc.2012.06.002.

8. Connor BA. Chronic diarrhea in travelers. Curr Infect Dis Rep. 2013;15(3):203-210. doi:10.1007/s11908-013-0328-2.

9. Stermer E, Lubezky A, Potasman I, Paster E, Lavy A. Is traveler's diarrhea a significant risk factor for the development of irritable bowel syndrome? A prospective study. Clin Infect Dis. 2006;43(7):898901. doi:10.1086/507540.
Research Highlights

\section{What Is Already Known?}

Acute, secretory diarrhea is the most common diarrhea profile among travelers. E. coli is the main microorganism found on the stool samples of international travelers in Bali.

\section{What This Study Adds?}

The study shows that secretory diarrhea among international travelers in Bali may also be related to Entamoeba spp. This uncommon finding warrants further research, especially in correlation with acute secretory diarrhea, Entamoeba spp., and immunity.

10. Statistik Bali Post. Wisatawan Mancanegara November 2015 capai 777,5 Ribu, Naik 1,70\% dari November 2014. https://www.bps. go.id/brs/view/id/1054. Published 2016.

11. Duggan C, Santosham M, Glass RI. The management of acute diarrhea in children: oral rehydration, maintenance, and nutritional therapy. MMWR Recomm Rep. 1992;41(RR-16):1-20.

12. World Health Organization. The treatment of diarrhoea: a manual for physicians and other senior health workers. Geneva, Switzerland: WHO; 2005.

13. Baron EJ, Miller JM, Weinstein MP, et al. A guide to utilization of the microbiology laboratory for diagnosis of infectious diseases: 2013 recommendations by the Infectious Diseases Society of America (IDSA) and the American Society for Microbiology (ASM) (a). Clin Infect Dis. 2013;57(4):e22-e121. doi:10.1093/cid/cit278.

14. Ahn JY, Chung JW, Chang KJ, et al. Clinical characteristics and etiology of travelers' diarrhea among Korean travelers visiting South-East Asia. J Korean Med Sci. 2011;26(2):196-200. doi:10.3346/jkms.2011.26.2.196.

15. Gascón J. Epidemiology, etiology and pathophysiology of traveler's diarrhea. Digestion. 2006;73 Suppl 1:102-108. doi:10.1159/000089785.

16. Gallardo F, Gascon J, Ruiz J, Corachan M, Jimenez de Anta M, Vila J. Campylobacter jejuni as a cause of traveler's diarrhea: clinical features and antimicrobial susceptibility. J Travel Med. 1998;5(1):23-26. doi:10.1111/j.1708-8305.1998.tb00451.x.

17. Vila J, Ruiz J, Gallardo F, et al. Aeromonas spp. and traveler's diarrhea: clinical features and antimicrobial resistance. Emerg Infect Dis. 2003;9(5):552-555. doi:10.3201/eid0905.020451.

18. Okhuysen PC. Traveler's diarrhea due to intestinal protozoa. Clin Infect Dis. 2001;33(1):110-114. doi:10.1086/320894.

19. Yu JR, Sohn WM. A case of human cyclosporiasis causing traveler's diarrhea after visiting Indonesia. J Korean Med Sci. 2003;18(5):738741. doi:10.3346/jkms.2003.18.5.738.

20. Gascon J. Epidemiology, etiology and pathophysiology of traveler's diarrhea. Digestion. 2006;73 Suppl 1:102-108. doi:10.1159/000089785.

21. Murphy H, Pandey P. Pathogens for travelers' diarrhea in Nepal and resistance patterns. Curr Infect Dis Rep. 2012;14(3):238-245. doi:10.1007/s11908-012-0253-9.

22. Peltola H, Gorbach SL. Traveler's diarrhea. In: DuPont HL, Steffen R, eds. Travel Medicine. 2nd ed. London: Decker; 2001.

23. Taylor DN, Houston R, Shlim DR, Bhaibulaya M, Ungar BL, Echeverria P. Etiology of diarrhea among travelers and foreign residents in Nepal. JAMA. 1988;260(9):1245-1248. doi:10.1001/ jama.1988.03410090077034. 